\title{
'You would not want to be the murderer of our dreams and options, right?'
}

\section{An analysis of the communication between university students} and their lecturer on the web 2.0

\author{
David Rodríguez Velasco | ORCID: 0000-0001-6608-8525 \\ Queen's University Belfast, Belfast, United Kingdom \\ d.rodriguez-velasco@qub.ac.uk
}

\author{
María Cecilia Ainciburu | ORCID: 0000-0003-4084-9909 \\ Nebrija University, Madrid, Spain; Siena University, Siena, Italy \\ caincibu@nebrija.es
}

Xiaoxu Katia Liu | oRCID: 0000-0001-5061-6274

Heilongjiang International University, Harbin, China

katialiu2017@163.com

\begin{abstract}
Studies of how adult Chinese speakers express disagreement at work or in business have a well-established tradition; whereas, studies on young students and university lecturers are scarcer. In general, the description of relationships with authority figures has been characterised by evidence of greater distance and a greater rituality than equivalent Western uses. The objective of this work is to verify whether, in a mutated communicative situation, students express their opposition to lecturer via email using predominantly indirect and attenuated linguistic forms - as might be expected —or whether linguistics changes are evident. For this purpose, 149 university students wrote a letter to their language lecturer in which they express their disagreement with the grade received. The results of the analysis reveal that, contrary to what was predicted, acts of direct speech are prevalent.
\end{abstract}

\section{Keywords}

negative politeness - disagreement - academic discourse - Chinese 
The traits that characterise the cultural behaviour of a given society are difficult to define; however, Chinese culture is represented as 'collectivist' in most empirical studies (Hofstede, 1980, 2001; Triandis, 1995; Schwartz, 1999, 2004). Simultaneously, the orientation of the Chinese individual in the group seems to be framed in the values of obedience to the social order and of respect to the hierarchy (Schwartz, 2004). Therefore, it is presupposed that, in this type of culture, courtesy is manifested in a marked way in the speech when the relationship between the interlocutors is asymmetric (Hofstede, 1980, 2001) and determines a complex linguistic negotiation when the required speech acts are not based on agreement or on the 'principle of solidarity' (Grice, 1975).

In the case of Chinese culture, and given the initial premises, there is evidence that similar speech acts, as opposed to the image of the interlocutor, such as the directive-giving form, even among peers, tend to be strongly mitigated (Chen \& Ringo, 2002). Directive acts, even when they include the verb in the imperative, include attenuating forms. Many researchers confirm this tendency of Chinese culture to have evasive, indeterminate or strongly mitigated postures (Bond, 1993; Young, 1994; Gao \& Ting-Toomey, 1998; Chen \& Ringo, 2002).

In recent years, however, many researchers have begun to point to profound changes in traditional culture, probably caused by access to new cultures through the media, new forms of art, an ever-increasing tourist movement, and the massive presence of new technologies (Zeng \& Greenfield, 2015; Unger, 2016; Wasserstrom, 2018). Is it possible that these changes will not affect the communication of young Chinese university students? We want to identify possible trends regarding the way in which Chinese university students use a form of virtual communication (e.g. email). To do so, we use as a trigger a situation that requires students dissenting with their lecturer to stimulate associated acts of speech, such as justification or complaint.

Studies based on linguistic analysis of computer-mediated communication (CMC) in Chinese are scarce or related to the field of business or company decisions, in which the interlocutors involved have a peer-to-peer relationship (Chen, Zhan \& Li, 2010). On the other hand, the study of emails written by Chinese students in English as a foreign language to lecturers is more frequent, and these can be compared with the data of this work due to the asymmetrical sender/receiver relationship and the academic environment in which they are contextualised (Xuehua, 2006; Zhu, 2012). Most of these studies focus on the speech act of requesting (Pan \& Cai, 2004; Zhu, 2012; Chen, 2015). 
From the pragmatic perspective, the speech act of request has a directive structure because it requires recipients to do something that they might not want to do (Chen, 2015). Academic communication usually involves a student writing to her/his lecturer to arrange an appointment or to obtain information, so that on most occasions this act of request is necessarily a vulnus to the 'face' of the student or lecturer (Zhu, 2012; Chen, 2015). In contrast, to oppose a professional judgement of a lecturer or to disagree with their scientific, political or personal statements represents an 'attack' from the communicative perspective. We, therefore, believe that studies on acts of speech of request, however useful, are not comparable with those of disagreement. Since the argumentative mode is the textual centre of academic and scientific discourses, it is possible that the study of the disagreement on which the argumentation is based will be more illuminating in the spirit of future scientific communication (Bathgate et al., 2015).

To account for the lack of agreement Xuehua (2006) studied a group of 60 Chinese students of English as a second language. As Table 1 illustrates, by conducting a series of Discourse Completion Tasks (DCTs), she categorised five possible ways of dissenting. The categorisation reproduces the most classical study of Brown \& Levinson $(1978,1987)$ and Kerbrat-Orecchioni (1997). The interest for our work is that the proposed situations include those of power symmetry and asymmetry among speakers. The results of Xuehua's research indicate that when the social status of the speaker is lower than that of the listener, which is what we are concerned with, senior students use more positive courtesy strategies and include a greater number of mitigators, although the Direct Strategy is prevalent. The correlation between greater attenuation and higher language level is evident. "Chinese EFL [English as a Foreign Language] learners are still not pragmatically competent enough to face situations involving the expression of disagreement" (Xuehua, 2006: 62). Therefore, we can deduce that the situation would require a greater use of mitigating elements, certainly in English, and probably in the mother tongue.

We believe that, in the words of Xuehua (2006), a relevant methodological problem is showed: it is generally taken for granted that the reason it is mitigated more in the higher levels is not only the greater availability of resources in the second language (L2), but also the transfer from the mother tongue. Although the intuition of the researcher as a native speaker is important, we lack linguistic samples in which Chinese students address lecturers in their L1. Without evidence, any possible transfer hypothesis is very weak. However, recent studies on foreign language identity seem to indicate that students are more courteous in L2 than in their mother tongue (Pavan, 2019); so, a lack of mitigating factors in the L2 discourse could be based on a lack of resources rather than on transfer. 


\section{Types of strategy Definition}
1. Direct Strategy Expressing disagreement directly and boldly with- out redressive action; having the most serious face threat, like counterattack, sarcasm, direct disagree- ment, contradiction, and so on.
2. Negative Politeness Oriented to the hearer's negative face, like account- Strategy ing, mitigating, and rhetorical questions.
3. Positive Politeness Oriented to the hearer's positive face, like partial Strategy agreement, pseudo-agreement, and conditioned agreement.
4. Hinting Strategy Implicitly expressing disagreement, like hints, and positive comment.
5. Avoidance Strategy Make non-commitment on the others opinions.

BASED ON XUEHUA, 2OO6: 57

Regarding Chinese language studies, Zhang (2016) analysed the request speech act of 44 university students and how mitigators such as “问候语 + 头 衔' (Greetings + Title) are used in the headings. Regarding the request speech act found in the body of the message, students prefer mostly direct ones just mitigated by '请' (please). Speech acts are classified into 'Most direct', 'Conventionally indirect' and 'Indirect', whether or not they are mitigating, regardless of the direction of the speech act (Positive or Negative Politeness Strategy, see Xuehua, 2006), with the first category being $65.5 \%$. Although the findings are mostly close to our goal, because the emails are written in Chinese, these results again come from texts that are only requests, not speech acts of disagreement.

We reused this classic categorisation of the strategies used in response speech acts, such as designs, so that the results of our study are comparable with those of Xuehua (2006). The aim of this research is to analyse how Chinese university students disagree with their lecturer's assessments when using emails in their academic environment. 


\section{$2 \quad$ Method}

The present study investigates the strategies used in an unequal situation (student/lecturer) by Chinese university students performing the speech act dissention in their mother tongue. Therefore, this research intends to answer the following question:

- Do Chinese students express their opposition to their lecturer using predominantly indirect and attenuated linguistic forms in a mutated communicative situation by email?

To answer the question, 149 Chinese students from Heilongjiang International University were selected for this study. The participants consisted of 131 females and 18 males, aged from 20 to 27 years old, who were studying in their final year. All the students were native Chinese speakers from different regions of China. In the pursuit of collecting dissenting emails, a pedagogical framework-based task was designed to elicit the data for this study. The instructions were as followed:

\section{想象一下你收到一封老师寄给你的有䏌你的 西班牙语口语期末考试成 绩的邮件, 你的得分为 4 分 (挂科, 满分 10 分, 5 分及格), 但是你并不认 同这个成绩。写一封邮件给你的老师Pedro Rodríguez Torres 表达你的 个人观点, 提出请求, 至少 125 个单词。}

[Imagine your lecturer has sent you the following email. You obtained a mark of 4 out of 10 [Fail, a full score is 10 and with 5 you pass the exam] in the final examination for the module of Oral Spanish and you do not agree with the mark given. Write an email to your lecturer Dr Pedro Rodríguez Torres showing your opinion along with any request you feel is necessary. Write a minimum of 125 words.]

To validate the data-collection instruments, a group of 10 second-year students were invited to complete the task. After analyzing the results, we realized that the statement was not clear enough, so the Chinese version was simplified to avoid possible misunderstandings. The instructions in the heading were also explained 你的得分为 4分 (挂科, 满分10分, 5分及格) [You fail the exam with a score of 4 . A full score is 10, with 5 you pass the exam], as the grading system at Helionjian Internation Univeristy was different to the data-collection instrument. Then the final version was again presented to several students so they could explain the objective of the task to check understanding. Once the task was understood, it was given to all fourth year students. The task simulated a situation in which the lecturer has sent to his students an email letting them 
know that the exam was failed. In this scenario, the subjects were expected to disagree with their lecturer. To recognise their sociopragmatic knowledge, a qualitative analysis was performed using MaxQDA. It examined the key text features in their writings focusing on their pragmatic moves related to politeness, degree of directness and internal/external modification devices in their emails. Data was analysed, constrasted and discussed by the authors in order to validate the results. After the data was identified and validated, the taxonomy from Xuehua's (2006) study was applied. However, due to the instruction of this study, which ask students to directly disagree with their lecturer, Xuehua's fifth strategy was removed, instead, Strategy 5 was replaced with the label "emotional strategy". This rhetorical category of 'captatio benevolentiae' (rhetoric used to seek to win someone's sympathy or support by showing respect), aims to analyse the number of times students used their feelings to win their lecturer's sympathy or support by expressing sadness, regret or shame. In classical rhetoric captatio benevolentiae was a similar resource to what we call "emotional strategy" here. However, we will use the second label as it is impossible to judge the final intention of the student in these cases and there is always the possibility that the exhibition of an emotional state is carried out with no intention of obtaining an advantage.

This paper does not intend to cite evidence in representation of Chinese interactional behaviour, as the corpus is too small to adequately represent China in terms of the typical methods of handling disagreement within the country. However, it highlights the strategy patterns used by these Chinese students in an academic context.

\section{$3 \quad$ Results}

A corpus of 149 emails was classified in line with Xuehua's (2006) taxonomy. Table 2 shows the distribution of disagreement strategies used by the subjects, but since the same text can contain multiple strategies, a more detailed analysis of the strategies is provided. Data were analysed according to the description of their responses and classified in consonance with the five most-used types of strategies. The category "strategy" has 442 occurrences in this corpus, with the distribution and the overall percentage also displayed in Table 2.

Once all the emails had been analyzed, the data showed that senior Chinese students preferred to disagree directly (Strategy 1: 47\%) despite being the most face-threatening strategy. Strategy 1 was used in 114 out of 135 emails. Students also employed mitigated strategies to soften the illocutionary force of their speech acts. Emotional strategy (Strategy 5) was found to be the most 
TABLE 2 Distribution of disagreement strategies used by the subjects and overall preference and percentage

\begin{tabular}{lccccc}
\hline & $\begin{array}{c}\text { Strategy 1: } \\
\text { Direct } \\
\text { strategy }\end{array}$ & $\begin{array}{c}\text { Strategy 2: } \\
\text { Negative } \\
\text { politeness } \\
\text { strategy }\end{array}$ & $\begin{array}{c}\text { Strategy 3: } \\
\text { Positive } \\
\text { politeness } \\
\text { strategy }\end{array}$ & $\begin{array}{c}\text { Strategy 4: } \\
\text { Hinting } \\
\text { strategy }\end{array}$ & $\begin{array}{c}\text { Strategy 5: } \\
\text { Emotional } \\
\text { strategy }\end{array}$ \\
\hline Emails $(\mathrm{N}=149)$ & 114 & 38 & 26 & 59 & 72 \\
Overall preference $(\mathrm{N}=\mathbf{4 4 2})$ & 209 & 43 & 28 & 67 & 95 \\
Overall percentage $(\mathrm{N}=\mathbf{1 0 0} \%)$ & 47 & 10 & 6 & 15 & 22 \\
\hline
\end{tabular}

used with 22\% (72/149 emails), followed by hinting strategy (Strategy 4: $15 \%$ in 59/149 emails), negative politeness strategy (Strategy 2: $10 \%$ in 38/149 emails) and positive politeness strategy (Strategy 3: 6\% in 26/149 emails).

\subsection{Strategy 1. Direct strategies}

When identifying the phrases of disagreement from the responses, the data reveal a high frequency of direct strategies, which were classified in four types: direct strategy [4], contradiction [3], counterattack [2] and others [1]. In this scenario, Chinese students prefered to dissent using bald-on record statements (see Figure 1). Among the 442 strategies found in the 149 emails, 209 were realeted to Direct Strategy. According to our data and in line to Xuehua's (2006) findings, it seems that students did not have the skill to employ an indirect and subtle way to express their contrasting ideas. Indeed, it seems that students tend to get to the point by disagreeing directly. This behaviour contrast Honglin's (2007) statement which pointed out that Chinese students hardly choose a direct refusal speech against their teachers. As results shows, among Strategy 1, direct strategy was the most chosen $(\mathrm{N}=127)$, followed by the use of contradictions $(\mathrm{N}=44)$, the substrategy "others" $(\mathrm{N}=3 \mathrm{O})$ and the use of counterattack $(\mathrm{N}=8)$. The substrategy "others" grouped those cases in which students attack their lecturer's professionalism by asking them, for instance, to change his minds on their marks or to double-check their grades (e.g. 我觉得西班牙语 口语的成绩有差错, 希望您可以核对一下我的成绩. I think there is something wrong with the score of spoken Spanish, I hope you can check my grade. [CH-

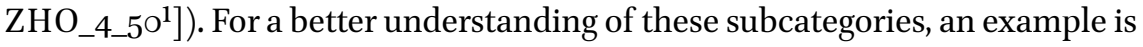
given in Table 3.

1 The labels in the examples coincide with those of the Nebrija-WOCAE corpus. CH-ZHO cor- 


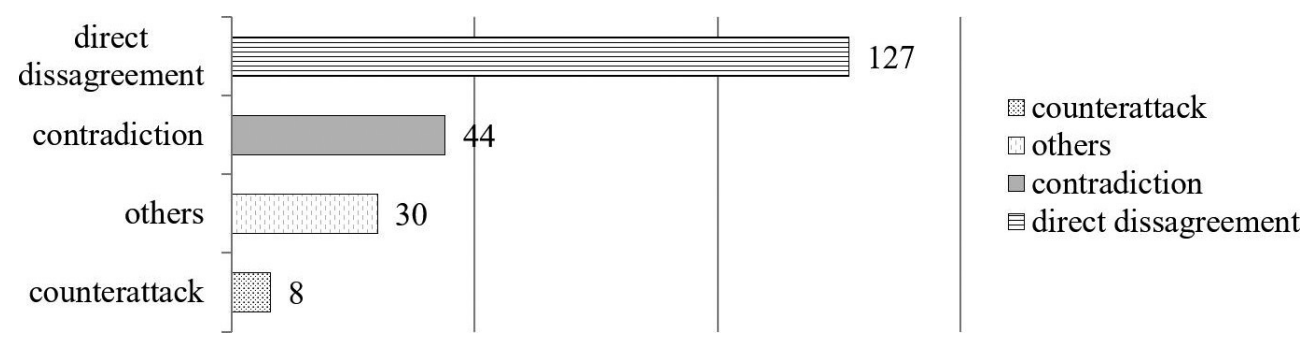

FIGURE 1 Direct strategies in Chinese academic emails

Regarding the corpus, the students tend to confront their lecturer by directly opposing their grade or defending their performance in the exam. The analysis of their phrases indicates that the students did not hesitate to display a very respectful but serious attitude towards their lecturer, even in an unequal situation (student/lecturer).

These results were expected, as they are similar to those found by Zhang (2016) regarding request speech acts, and by Xuehua (2006) regarding dissentive acts. Both studies reveal the preference of Chinese students for using Direct Strategy. Comparing the data obtained by Xuehua (2006: 58), our senior students use direct strategies more often (47\%) than Xuehua's: $40 \%$ in sophomores and $34 \%$ in seniors. It is possible that our results are more reliable because they are contextualised and not coming from Discourse-Completion Tasks (DCTs), but from pedagogical tasks. What is shared with the Xuehua study is the diffuse use of sub-strategies in seniors, although in our case the richness of these is greater (see Figure 2).

\subsection{Strategy 2. Negative politeness ptrategies}

To avoid causing offence and to reduce hostility, phrases that displayed deference were used. Negative Politeness Strategies were employed 43 times, which could indicate the students' concern when disagreeing with a person of authority in an unequal situation. Examples of these uses are illustrated in Table 4, in which it is evident how students apply Strategy 2 to manifest their concerns while considering their lecturer's superior status (Xuehua, 2006).

As the data from the corpus reveal, negative politeness strategies were used to acknowledge the distance between the interlocutors, to avoid imposing themselves and to provide options to the receiver. However, this approach was

respond to the name and language of the corpus, followed by the academic year and the example number $\left(4_{4} 5^{\circ}\right)$. However, since the loading of the corpus is still in progress, some example may be missing, but will be visible soon. 
TABLE 3 Example of Direct Strategy found in the corpora written by Chinese students

\section{Examples}

[1]. 我不喜欢这个分数, 甚至对这个 分数有质疑. 我觉得我不应该取得这 公糟糕的成绩, 如果可以的话, 希望 您重新考虑一下。

[CH-ZHO_4_11]

\section{Translation}

[1]. I don't like this mark; I even have doubts about it. I don't think I deserve such a bad result. If possible, I hope you could double check the mark.
[2]. 老师, 我觉得您肯定是弄错了, 要不您再核对一遍好吗?

[CH-ZHO_4_2O]

[3]. 因为我不相信的我西班牙语口语 考试挂科了我不认同。我觉得我西 班牙语说的非常好同时我也回答了 所有您提的问题。

[CH-ZHO_4_124]

[4]. 我对这个最终成绩不同意。我 认为我的平时成绩和我的考试成绩 都不应该是低分。因此我对我所得 的4分的公平度表示怀疑, 我不认为 这是我正常该得的分数。

[CH-ZHO_4_34]
[2]. Teacher, I think you must have made a mistake. Would you please check it again?

[3]. As I can't believe I failed my Spanish oral exam, I don't agree with it. In my opinion, I speak Spanish very well and I managed to answer all your questions.

[4]. I disagree with this final result. I don't think my daily performance grades and my test scores should be that low. So, I doubt the fairness of the four points I got. I don't think this is the mark I deserve.

seen in 38 out of 149 emails, which represents only a $10 \%$ of the overall percentage of strategies found in the corpus, as illustrated in Table 2. The examples from Table 4 reveal how students emphasised the little time available to their lecturer because of his multiple occupations [8] to provide the opportunity to the listener to say no to a request or to maintain his position in the disagreement. The use of apology formulas [7] or interrogative statements [6] were also some of the strategies chosen by the students to mitigate their imposition on the hearer. 
TABLE 4 Example of Negative Politeness Strategy found in the corpora written by Chinese students

Examples

[5].我尊重您的看法, 但我不同意这 个结果, 老师, 希望您改变看法。 [CH-ZHO_4_12]

[6]. 您能允许我查询详细的分数 吗?让我了解我到底错在了哪一部 分。

[CH-ZHO_4_37]

[7]. 如果分数无误, 很抱歉劳烦您。 [CH-ZHO_4_37]

[8]. 你有空闲时间吗? 我想去拜访

您, 请您指出我的一些问题, 让我能 够日益改进自己。

[CH-ZHO_4_63]

\section{Translation}

[5]. I respect your evaluation, but I don't agree with this result, lecturer. I hope you can change your opinion.

[6]. Would you allow me to check the mark breakdown, so I know where I made a mistake?

[7]. If the mark is correct, I am sorry to bother you.

[8]. Do you have free time? I'd like to visit you so you can point out my mistakes so that I can improve.

\subsection{Strategy 3. Positive politeness strategies}

Generally, the subjects were not skilful at employing the indirect and implicit methods to express their disagreements, which explains why fewer strategies of positive politeness were found. The Chinese students depended on partial agreement, total agreement and conditional agreement to hide their full opinions (see Figure 2). The students tried to avoid making direct statements and preferred to make promises and deductions to express their points of view. The data reveal that Strategy 3 was used 28 times, appearing in 26 emails. When the examples were further examined, we found that most of the students preferred to use partial agreement (13/28 cases found), closely followed by total agreement (12/28). Conditional agreement was the least substrategy used with only 3 examples found in corpus. Looking at the results, it seems that students did not consider the power or social distance between them and their teacher. Had these factors been taken into account, it may have influenced their pragmalinguistic choices when writing their emails, which could have prevented potential distressful consequences in their lecture's public face. More examples of the employment of the positive politeness strategy are listed in Table 5 . 


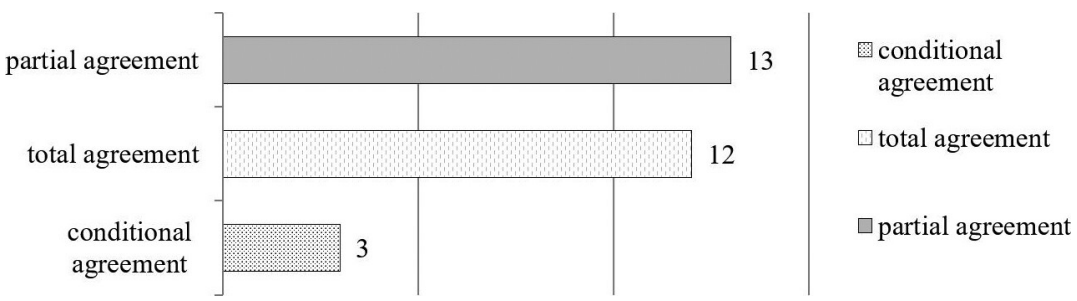

FIGURE 2 Positive politeness strategies in Chinese academic emails

TABLE 5 Examples of Positive Politeness Strategy found in the corpora written by Chinese students

\section{Examples}

\section{Translation}

[9].我已收到您的消息, 我不敢相信 我居然挂科了! 但冷静下来思考过 后, 我觉得这是正常的结果因为我 平常不怎么练习口语更不会用西班 牙语和同学交流。

[CH-ZHO_4_132]
[9]. I got your email. Unbelievably, I failed, but after thinking about it calmly, I think this is natural because I barely practise Spanish even with my classmates.
[10]. 成绩是真实的, 我并无抱怨和 愤满。

[CH-ZHO_4_121]
[10]. The grade is correct, and I have no complaints or anger.
[11]. 我知道我在口语考试中存在很多 [11]. I know that I had a lot of prob问题，很少的词汇量和很多的语法 错误。但是我还是觉得至少我可以 通过考试的。

[CH-ZHO_4_123] lems in the oral exam, like very little vocabulary and a lot of grammar mistakes. But, I still feel that at least I should pass the exam.

[12]. 我的分数并不理想, 我不知道是 [12]. My mark is not very good. I don't 否分数有误, 不过我上学期确实没 有好好的去练习口语, 考试的时候 有一点紧张, 和老师的对话不是很 流畅。

[CH-ZHO_4_119] know if the mark is wrong. However, I didn't practise my speaking last semester. I was a little nervous when I took the exam. The conversation with the teacher was not very smooth. 
The use of positive politeness to display understanding [11] [12], agreement [9] and approval of the speaker [10] with the addressee's claims was the least prevalent strategy in our corpus, with just $6 \%$. These results, compared with Xuehua's (2006) senior students ( $26.27 \%$ vs. $6.33 \%)$, prove the lack of knowledge of our pupils to reduce the damage of a potential threat, which leads us to believe that 'the subjects' awareness of using this kind of strategy needed to be much enhanced" (Xuehua 2006: 59).

\subsection{Strategy 4. Hint strategies}

To reveal the disagreement while maintaining 'face' and for relationship management, students used hint strategies. What Goffman (1967) calls 'facework' means "avoiding face-threatening acts but performing face-maintaining acts or face-enhancing acts to save face for themselves or others" (Zhu, 2014: 85-101). In this communication via email, the students tended to use these polite statements to maintain the harmony of the relationship with the lecturer, which could explain why hint strategies were the third most-used strategy: used 67 times in 59 out of 149 emails ( $15 \%$ of the corpus). Brown \& Levinson (1987: 60) state that some communicative acts, such as the speech act of disagreement, "intrinsically threaten face" and make recipients feel bad. The students' emails indicate that they tried not to put at risk their academic record by avoiding offence or hostility towards their lecturer. This conduct coincides with Brown \& Levinson's theory (1987). As Table 6 shows, students were very careful with the vocabulary they used in their emails, attempting to express what they felt without jeopardising the interpersonal relationship.

Questioning [13] [15] [16] and doubting [14] the lecturer's grades was the most common form to express disagreement without being too direct. This strategy was the third most used, which, compared with Xuehua's (2006) senior students ( $5.88 \%$ vs. $15.15 \%)$, makes us think that our pupils performed better in redressing the threat to the interlocutor's positive face. These percentages, as we previously mentioned, might be more reliable than Xuehua's because they are contextualised and do not come from DCTs.

\subsection{Strategy 5. Emotional strategy}

The social distance between the students and the lecturers means that the students tend to apply various strategies to reduce the unequal status in their disentive acts. Emotions are very effective for regulating social distance and announcing intentions (Markus \& Kitayama, 1991), as they are "closely related to the nature of the relationship, reflecting an important function [...] at the interpersonal level" (Ficher \& Manstead, 2008: 458). In Chinese culture, students favour harmony, and their negative and strong emotions are supressed 
TABLE 6 Examples of Hint Strategy found in the corpora written by Chinese students

Examples

[13]. 我对我的成绩有一些问题。 [CH-ZHO_4_131]

[14]. 但是矢于最终期末考试的分数 问题我心中仍有些许疑问, 在这封 邮件中我想与您详谈一下此事。 [CH-ZHO_4_140]

\section{Translation}

[13]. I have some doubts about my grades.

[14]. I still have some doubts about the final exam score. I want to talk to you about this in this email.
[15]. 对此, 我有一些疑问需要您解 答。我在口语考试中的表现, 我认为 还不错, 并且在考试时老师问的问 题, 我回答的也可以老师也说不错, 但最后的成绩却没有及格。对此我 十分困惑。

[CH-ZHO_4_69]
[15]. About this, I have some unanswered questions. In my opinion, my performance was not so bad, and I had pretty great answers to the teacher's questions but, ultimately, I failed, that's why I am so confused now.

[16]. I have a few questions about the Spanish speaking exam that I need to ask you.

to maintain this status (Gao, 2008; Cheng \& Tsui, 2009; Liu, 2014). However, the data reveal how emotions were used to cover the students' feelings while trying to change their lecturer's points of view. Our results are in line with this socio-cultural pattern as Strategy 5 was found in 95 phrases $(22 \%$ of the total number of strategies used), in which feelings were used to convince the listener in nearly half the corpus $(72 / 149)$. This practice represents the second-most adopted strategy following the usage of direct disagreement. For a better understanding of this strategy, some examples are given in Table 7 .

Sadness [18], surprise [19], frustration [20] or even envy [17], as evidence these examples, are some of the emotions found in the corpus. A large number of the students expressed themselves through expressive dissenting speech acts (Herrero-Moreno, 2002), which, in some cases, seems to be exaggerated. All the phrases indicate that the students were attempting to win sympathy or support by making the lecturer feel guilty, for example 哦, 天哪, 真的是太不 幸了(oh, my God, how unfortunate! [CH-ZHO_4_36]); 这让我太意外了 (I am so 
TABLE $7 \quad$ Examples of Emotional Strategy found in the corpora written by Chinese students

\section{Examples}

[17]. 我不能接受的是, 我的口语搭档 比我说的要差但是她的分数比我高。 希望老师您能尽快解决我的疑问。 [CH-ZHO_4_68]

\section{Translation}

[17]. What I can't accept is that my partner in the exam is worse than me, but her mark is higher than mine. I hope the teacher can address my doubt as soon as possible.

[18]. 是因为我说的很不够好? 还是课 堂表现不好?或者您不喜欢我。那样 对我我很伤心的。

[CH-ZHO_4_38]
[18]. Is it because I did not speak so well or because of my daily performance, or just the fact that you don't like me? Because if this is true, I would be so sad.
[19]. 您能告诉我我不及格的原因是什 公吗? 我迫切的想知道, 不然我的无 法生活的开心。 [CH-ZHO_4_97]
[19]. Could you tell me why I failed? I am eager to know, or I cannot live happily.

[20]. 您不会做这个杀死梦想和选择 的刽子手的, 对吗?

[20]. You would not want to be the mur[CH-ZHO_4_121] derer of our dreams and options, right?

surprised! [CH-ZHO_4_36]); 这是我第一次挂科, 因为这个我都没有吃饭, 只喝了一些水, 是真的不开心呀! (This is the first time I failed. Because of this, I have been having nothing but water, I am very unhappy [CH-ZHO_4_40]). All these sentimental phrases display the expressiveness of our senior Chinese students' feelings. Many students expressed their shame by asking for forgiveness for failing the exam: 我很难过没有通过口语考试 (Ifeel very sorry about failing this exam [CH-ZHO_4_51]); 矢于这次考试我感到很抱歉 (I'm sorry I didn't pass the test [CH-ZHO_4_4]) or 冒昧的给您发送这封邮件, 内心真的 觉得十分愧疚 (Sorry to send you this email, I feel very ashamed about my mark [CH-ZHO_4_117]). However, the students explicitly expressed anger also: 但是 我觉得这样有些不公平 (Really, Ifeel that my mark is unfair [CH-ZHO_4_53]); 老师, 你最近还好吗? 我想, 给您写这封邮件的时候, 我是非常沮丧的 (How are you? I don't know how you are, but I'm in bad shape because I didn't pass the test [CH-ZHO_4_48]). All these examples prove how emotional sensi- 
tivities were very often used to try to manipulate the lecturer's feelings, which could influence, increase or jeopardise the social relationship.

\section{Discussion}

As is evident in previous investigations, Chinese social behaviour tends to be evasive and indeterminate (Bond, 1993; Young, 1994; Gao \& Ting-Toomey, 1998; Chen \& Ringo, 2002). Chinese culture emphasises the relationship of a person with the group to which he or she belongs and highlights the importance of the connection between different members of the group and common good. For individuals in a collectivist culture, the main objective is to protect the relationship between those in their circle (Markus \& Kitayama, 1991). Chinese cultural values promote social harmony and the fulfilment of the obligations and responsibilities of each individual (Matsumoto \& Juang, 2004). It has been said that the Chinese are inclined to avoid provoking conflict by desisting from making direct statements to avoid friction (Xuehua, 2006; Tuan, 20o9; Zhang, 2016). However, as is apparent in our data, our results contradict that statement. Our students preferred to use direct disagreement strategies, contradicting or even counterattacking their lecturer to express their beliefs, which creates the impression that the student wants to impose her/his will.

Our results contradict those from Liu \& Littlewood (1997), Cheng \& Tsui (2009) and López-Ozieblo (2017), which claim that Chinese native speakers are reluctant to take an active role in disagreements. Direct disagreement, followed by contradictions, were the two most-used strategies in our corpus. This form of writing emails "causes a negative effect on the perception of the reader, who may feel obliged, even while in his duty as a teacher, to meet the requests imposed by the student" (Rodríguez-Velasco 2019: 220). Examples such as 这 次期末成绩我只得了 4 分, 但是我觉得我应该得到更高的分数 (I only got 4 points for the final grade this time, but I think I should get a higher score [CHZHO_4_3]); 希望您重新核实分数, 给予我合理的解释 (I hope you recheck the score and give me a reasonable explanation [CH-ZHO_4_8]) or 但我不同意这 个结果, 老师, 希望您改变看法 (I disagree with this result, teacher, I hope you change your opinion [CH-ZHO_4_12]) were just some of the cases used by the Chinese students to oppose their lecturer directly. This direct confrontation, plus the small number of positive and negative politeness strategies accentuate the imposition on their claims.

A lack of sufficient use of both forms of politeness meant that the students neglected to maintain a safe distance from their face-threatening acts, failing to understand that these types of courtesy provide a safeguard to save 
or maintain one's, as well as the other person's, self-image. Cases such 我希 望老师能在给我一次机会, 让我证明自己是可以获得一个好的分数 (I hope the teacher can give me a chance to prove that I can get a good score [CH-ZHO_4_35]) or 你有空闲时间吗? 我想去拜访您, 请您指出, 我的 一些问题让我能够日益改进自己 (Do you have free time? I want to visit you, please point out that some of my problems allow me to improve myself $[\mathrm{CH}-$ ZHO_4_63]) were some of the few examples in which negative politeness was found. As Padilla-Foster (2016) points out, the use of mitigating devices, such as preparators, grounders, disarmers or promise of a reward, displays the interlocutor's good will. These strategies promote cooperation and help to reduce the imposition of the requests by saving face and avoiding communication problems. Since the use of indirect strategies offers the impression that the lecturer has more freedom to comply with the request made, the lack of their use might be one of the reasons the tone of our students' emails are so direct, as noted by Biesenbach-Lucas (2007) and Alcón-Soler (2013).

'Hints' were another of the strategies that our students used to express disagreement implicitly. As stated previously, the use of hints avoids provoking conflict by desisting from making direct statements. As Char et al. (1980: 61) said, "a frequent misconception about the traditional Chinese is that they say 'yes' when they mean 'no' and vice versa". This assertion implies that, in Chinese culture, it is considered impolite to deny a request directly. Therefore, by questioning the hearer's commitment or feasibility or starting potential, grounders are commonly used to convey the message. "Such hints are also often used as adequate support for the more direct requests" (Gao, 1999: 84); however, our students did not praise in such a way, but instead sought a more radical, tothe-point method of expressing their opinions.

Considering the results, it seems that the students tried to mitigate all this abruptness and directness by expressing emotions that target their lecturer's compassion. 对于我所获得的西语口语分数我感到非常的吃惊和伤心, 我 觉得真是太不可思议了, 我竟然没有通过您的考试 (I am very surprised and sad about the score I have received in spoken Spanish. I think it's incredible. I didn't pass your exam [CH-ZHO_4_35]) or 您不会做这个杀死梦想和 选择的刽子手的, 对吗? (You would not want to be the murderer of our dreams and options, right? [CH-ZHO_4_121]) were just some of the most-direct expressions of feelings. One aspect that cannot be overlooked, since it affects emotional complexity, is the cultural component of each individual. The culture to which we belong influences and determines the expression and manifestation of emotions (Imada \& Ellsworth, 2011; Caldwell-Harris et al., 2013; Plebe \& De la Luz, 2015; Yang \& Wang, 2016; Keshtiari \& Kuhlmann, 2016; Errasti et al., 
2018). Each culture defines values that are (un)acceptable and, since human beings are guided by the pre-established values of their culture, their capacity to express emotions is subject to their norms and restrictions. These cultural values are what guide our behaviour in different social events, which can influence both our behavioural patterns and our emotional experiences (Kitayama et al., 2000).

What is peculiar in our case is how our Chinese speakers, who come from a culture distinguished for its civility, politeness, decorum (Freshley, 2005; Gao, 2008; Cheng \& Tsui, 2009; Liu, 2014), were unable to control their negative or strong emotions to maintain a harmonious interpersonal relationship with their lecturer. Regarding the aforementioned examples, the students are seemingly trying to blackmail their lecturer by making him feel bad about the given mark, or even insinuating unprofessional behaviour, as stated in Example 18: Is it because I did not speak so well or because of my daily performance, or just the fact that you don't like me? Because if this is true, I would be so sad. Throughout the corpus, it is evident that the most-used emotion strategy is sadness. The students expressed their sorrow by explaining how bad they feel or how much they want to pass their exam. Disbelief and confusion were also two of the most-recurrent emotions. This type of behaviour, unacceptable in a Western context, might be explained, in Chinese culture, because "the social order exists independently of any emotion, and emotions are thought of as lacking the power to create, maintain, injure, or destroy social relations" (Potter, 1988: 186). Nonetheless, the abruptness of the students' expressions, combined with the few examples related to positive politeness and the scarcity of strategies used to prepare the addressee for the subsequent request to provide reasons that justify their demands or to avoid the possibility of a refusal, reveal the lack of pragmalinguistic competence of these students. These results lead us to agree with Betti (2013) regarding the need for instruction of native speakers in the correct form of writing emails in an academic context.

The results of this research reveal that there are differences between the level of attenuation expected in the speech act of dissenting in the computer-mediated communication (CMC) of Chinese university students and the directivity of the speech acts analysed in the samples. The trend in previous foreign language studies indicates that direct speaking acts occurred in correlation with a lack of marker knowledge (e.g. a lack of strategic attenuation resources at low lev- 
els). At higher levels, attenuation was more frequent. Our results, in the mother tongue, contradict or at least resize the hypothesis of direct transfer of strategic courtesy patterns in the speech acts of Chinese speakers.

Other strategies used, such as the display of feelings and captatio benevolentiae consolidate two ideas:

1. On the one hand, the argument chosen as the trigger of the email (the student-lecturer contrasting opinion regarding the final grade of a course) is fruitful for deploying a relevant number of pragmatic strategies (greater than that deployed in request emails and in a foreign language) (Biesenbach-Lucas, 2007; Alcón-Soler, 2013).

2. On the other hand, the social harmony of the discourse that dominates the communication described by other authors is not the goal that students have in mind when they feel criticised by the lecturer.

A hypothesis of change between the patterns of cultural analysis described in traditional communication and the samples of a new type of communication seems to be confirmed. The fact that this change happens among young university students could constitute a trend that deserves to be confirmed with diachronic studies and contrasted with generations that have not been exposed to the Internet, which is difficult without leaving the ambit of the academic community.

A limitation of the present study concerns the fact that our results need to be treated with caution, as the corpus is too small to represent typical Chinese methods of handling disagreement. As aforementioned said, it has not the intention to cite evidence in representation of interactional behaviour within the country, but to form a more complete picture of the pragmatic awareness and competence of this particular group. This study was limited in several other ways as well. First, it was limited regarding the medium (electronic mails) and scope of communication, as a the present study analysed only native speakers' data and no comparison with non-native speakers' was carried out using the same context. By doing so, it would have allowed us to reinforce our claims regarding the interlanguage-specific features of these emails and the pragmatic awareness of the students. Second, it focused only on the strategies related to disagreement, while other sorts of pragmatic movements related to politeness, such as the (in)formality of their form of address and farewells, were excluded. Third, it could be also criticised the adoption of Strategy 5 (emotional strategy) as a strategy to disagree. Although it may not be considered as a dissenting act by itself, the quantity and quality of these sentences make them a separate phenomenon that deserves further inquiry. This strategy was implemented when Xuehua's (2006) taxonomy could not be applied. It grouped those examples in which students exhibited their feelings as a strategy to persuade their lec- 
turer. Although Strategy 5 may overlap with other categories, such as Xuehua's hinting strategy, we cannot be certain if this author has considered it under another label as this study lacks of a published corpus. Finally, another aspect that could be judged is the students' current pragmatic competence, as the use of resources was allowed in this study. Nevertheless, it is necessary to point out that, in real situations, when writing an email is needed, the recipient depends on various resources to determine the best approach to address their interlocutor and express their thoughts. Therefore, we wanted to emulate this scenario while gathering data in order to form a more complete picture of the pragmatic awareness and competence of our students.

Further research is needed to examine all the previous factors mentioned, and it is hoped that in the future, larger scale studies will be conducted in which Chinese students address young and old lecturers in their own language, because it is possible that the variation of the remote reader will influence the expression of disagreement.

\section{Acknowledgments}

This study was supported by the Agencia Estatal de Investigación (AEI, National Research Agency) under the project "Emotion, memory, linguistic identity and emotional acculturation (EMILIA)" (Ref. FFI2017-83166-C2-2-R) , and was carried out within the framework of the research project IN.MIGRA3-CM (ref. H2019/HUM5772), funded by the Community of Madrid and co-funded by the European Social Fund.

\section{References}

Alcón-Soler, Eva. 2013. Pragmatic variation in British and International English language users' email communication: A focus on requests. RESLA 26: 25-44.

Bathgate, Meghan, Amanda Crowell, Christian Schunn, Mac Cannady \& Rena Dorph. 2015. The learning benefits of being willing and able to engage in scientific argumentation. International Journal of Science Education 37: 1590-1612.

Betti, Silvia. 2013. "Hola profe!" ¿Son corteses los jóvenes en el correo electrónico? Estudio de mensajes virtuales españoles e italianos enseñanza y aprendizaje de la pragmática de una lengua extranjera. RESLA 26: 67-89.

Biesenbach-Lucas, Sigrun. 2007. Students writing emails to faculty: An examination of e-politeness among native and non-native speakers of English. Language Learning \& Technology 11: 59-81. 
Bond, Michael Harris. 1993. Emotions and their expression in Chinese culture. Journal of Nonverbal Behavior 17: 245-262.

Brown, Penelope \& Stephen Levinson. 1978. Universals in language usage: Politeness phenomena. In S. Goody (ed.), Questions and Politeness, 56-89. Cambridge: Cambridge University Press.

Caldwell-Harris, Catherine, Ann Kronrod \& Joyce Yang. 2013. Do more, say less: Saying "I love you" in Chinese and American cultures. Intercultural Pragmatics 10: 4169.

Char, Walter. 1980. The Chinese. In J.F. McDermott, W. Tseng and T.W. Maretzki (eds), People and Cultures of Hawaii. A Psychocultural Profile, 143-186. Honolulu: University of Hawaii Press.

Chen, Guo-Ming \& Ma Ringo. 2002. Chinese Conflict Management and Resolution. London: Ablex Publishing.

Chen, Hao, Yan Zhan \& Yan Li. 2010. The application of decision tree in Chinese email classification. In Proceedings of the 2010 International Conference on Machine Learning and Cybernetics: $305-308$.

Chen, Yuan-Shan. 2015. Developing Chinese EFL learners' email literacy through requests to faculty. Journal of Pragmatics 75: 131-149.

Cheng, Winnie \& Amy Tsui. 20o9. "Ahh laugh well there is no comparison between the two I think": How do Hong Kong Chinese and native speakers of English disagree with each other? Journal of Pragmatics 41: 2365-2380.

Errasti, José, Isaac Vázquez, Manuel Villadangos \& Joaquín Moris. 2018. Differences between individualist and collectivist cultures in emotional Facebook usage: Relationship with empathy, self-esteem, and narcissism. Psicothema 30: 376-381.

Ficher, Agneta \& Anthony Manstead. 20o8. Social functions of emotion. In M. Lewis, J.M. Haviland-Jones \& L. Feldman Barrett (eds), Handbook of Emotions, 456-470. New York, NY: The Guilford Press.

Flowerdew, John \& Lindsay Miller. 1995. On the notion of culture in L2 lectures. TESOL Quarterly 29: 345-373.

Freshley, Dwight. 2005. A crosscultural study of identification of emotions: China and the United States. Intercultural Communication Studies 14: 171-175.

Gao, Ge \& Stella Ting-Toomey. 1998. Communicating Effectively with the Chinese. London: SAGE.

Gao, Hong. 1999. Features of request strategies in Chinese. Working Papers 47: 73-86.

Gao, Xuesong. 2008. Teachers' professional vulnerability and cultural tradition: A Chinese paradox. Teaching and Teacher Education 24: 154-165.

Goffman, Erving. 1967. On Face-work: An Analysis of Ritual Elements in Social Interactions. Oxford: Aldine.

Grice, Paul. 1975. Logic and conversation. In P. Cole \& J.L. Morgan (eds), Syntax and Semantics: Speech Acts, 41-58. New York, NY: Academic Press. 
Herrero-Moreno, Gemma. 2002. Los actos disentivos. Verba. Anuario Galego de Filoloxía 29: 221-242.

Hofstede, Geert. 1980. Culture's Consequences: International Differences in Work-related Values. Beverly Hills, CA: SAGE.

Hofstede, Geert. 2001. Culture's Consequences: Comparing Values, Behaviours, Institutions, and Organizations across Nations. Thousand Oaks, CA: SAGE.

Imada, Toshie \& Phoebe Ellsworth. 2011. Proud Americans and lucky Japanese: Cultural differences in appraisal and corresponding emotion. American Psychological Association 11: 329-345.

Kerbrat-Orecchioni, Catherine. 1997. A multilevel approach in the study of talk-ininteraction. Pragmatics 7: 1-18.

Keshtiari, Niloofar \& Michael Kuhlmann. 2016. The effect of culture and gender on the recognition of emotional speech: Evidence from Persian speakers living in a collectivist society. IJSCL 6: 1-16.

Kitayama, Shinobu, Hazel Rose Markus \& Masaru Kurokawa. 20oo. Culture, emotion, and well-being: Good feelings in Japan and the United States. Cognition \& Emotion 14: 93-124.

Liu, Chun. 2014. Chinese, why don't you show your anger? A comparative study between Chinese and Americans in expressing anger. International Journal of Social Science and Humanity 4: 206-209.

Liu, Ngar-Fun \& William Littlewood. 1997. Why do many students appear reluctant to participate in classroom learning discourse? System 25 : 371-384.

López-Ozieblo, Renia. 2018. Disagreeing without a 'no': How teachers indicate disagreement in a Hong Kong classroom. Journal of Pragmatics 137: 1-18.

Markus, Hazel Rose \& Shinobu Kitayama. 1991. Culture and the self: Implications for cognition, emotion, and motivation. Psychological Review 98: 224-253.

Matsumoto, David \& Linda Juang. 2004. Culture and Psychology. Los Angeles: Wadsworth.

Padilla-Foster, María. 2016. La comunicación intercultural: pragmática de la petición en español y en chino mandarín. PhD dissertation, Universidad Complutense de Madrid.

Pan, Bingxin \& Junmei cai. 2004. 中美大学生电子邮件文本对比研究 Contrastive analysis of email texts between Chinese students and United States' students. Journal of Xian Institute of Foreign Studies 12: 26-29.

Pavan, Elisabetta. 2019. Politeness, intercultural communication, e-mails: Principles and practices. In P. Romanowski \& E. Bandura (eds), Intercultural Foreign Language Teaching and Learning in Higher Education Contexts, 45-70. New York: IGI Global.

Plebe, Alessio \& Vivian de la Luz. 2015. When language shapes perception. RIFL 2: 4257 . 
Potter, Sulamith Heins. 1988. The cultural construction of emotion in rural Chinese social life. Ethos 16: 181-208.

Rodríguez Velasco, David. 2019. Análisis de los elementos pragmáticos en la interacción escrita académica: el caso de los correos electrónicos de universitarios norteamericanos. Revista Nebrija De Lingüística Aplicada a La Enseñanza De Lenguas 13: 198225 .

Schwartz, Salomon. 1999. A theory of cultural values and some implications for work. Applied Psychology: An International Review 48: 12-47.

Schwartz, Salomon. 2004. Mapping and interpreting cultural differences around the world. In H. Vinken, J. Soeters \& P. Ester (eds), Comparing Cultures: Dimensions of Culture in a Comparative Perspective, 43-73. Leiden: Brill.

Triandis, Harry. 1995. New Directions in Social Psychology: Individualism and Collectivism. Boulder, CO: Westview Press.

Tuan, Jeanne. 2009. An analysis of indirectness in disagreement: A corpus study on intercultural conversations between Taiwanese and Native Speakers of English. ShuTe Online Studies of Humanities and Social Sciences 52:13-38.

Unger, Jonathan. 2016. The Transformation of Rural China. New York: Routledge.

Wasserstrom, Jeffrey. 2018. Popular Protest and Political Culture in Modern China. New York: Routledge

Xuehua, Wu. 2006. A study of strategy use in showing agreement and disagreement to others opinions. CELEA Journal 29: $55^{-6} 5$.

Yang, Yang and Qi Wang. 2016. The relation of emotion knowledge to coping in European, American and Chinese immigrant children. Journal of Child and Family Studies 25: $45^{2-463}$.

Young, Linda. 1994. Crosstalk and Culture in Sino-American Communication Studies in Interactional Sociolinguistics. Cambridge: Cambridge University Press.

Zeng, Rong \& Patricia Greenfield. 2015. Cultural evolution over the last 40 years in China: Using the Google Ngram Viewer to study implications of social and political change for cultural values. International Journal of Psychology 50: 47-55.

Zhu, Wuhan. 2012. Polite requestive strategies in emails: An investigation of pragmatic competence of Chinese EFL learners. RELC Journal 43: 217-238.

Zhu, Wuhan. 2014. Managing relationships in everyday practice: The case of strong disagreement in Mandarin. Journal of Pragmatics 64: 85-101. 